УДК 330.7

DOI: $10.17223 / 22229388 / 20 / 7$

\section{Т.В. Счастная}

\section{О РАЗВИТИИ РЫНКА ПРЕМИАЛЬНОГО БАНКОВСКОГО ОБСЛУЖИВАНИЯ В РОССИИ}

Современный банковский рынок становится все более клиенто-ориентированным. Одним из перспективных сегментов этого рынка является премиальное банковское обслуживание, появившееся в России в последние 5-7 лет. Проанализированы причины, вызвавшие интерес банков к премиальному банковскому обслуживанию. Отмечены особенности и факторы, влияюшие на его развитие в России и в мире. Выявлены недостатки, сопутствуюшие развитию премиального банковского обслужсивания в России. Важный теоретический и методологический аспект изучения премиального банковского обслуживания связан с более четкой дифференциачией самого понятия.

Ключевые слова: премиальное банковское обслужсивание, эксклюзивное банковское обслуживание, сегмент рынка, «премиальные программы»».

Премиальное банковское обслуживание (ПБО) проникло на российский банковский рынок с начала 2000-х гг. В 2002 г. на рынок вышел Сити-банк, основная масса игроков появилась в 2009-2011 гг. Это крупнейшие частные банки: Альфа-Банк, Райффайзенбанк, ЮниКредит Банк. В 2011 г. пришли крупные государственные банки - Сбербанк и ВТБ 24. В настоящее время 19 из 25 крупнейших банков предлагают своим частным клиентам программы премиального обслуживания. А сам рынок, несмотря на незначительный возраст, прошел не только стадию становления, но и обновления, перезапуска, имеет обширные планы совершенствования и с точки зрения количественного роста, и качественного наполнения. Однако текущая негативная рыночная ситуация и рост числа бедных граждан создают ряд проблем для развития такого сегмента банковского рынка.

По данным Всероссийского центра изучения общественного мнения (ВЦИОМ) в России увеличивается число бедных граждан. Это несомненно окажет существенное влияние на развитие экономики, особенно еe потребительского сектора, а также на развитие сектора финансовых услуг (и банковских, в частности). «...Количество российских семей, доходов которых не хватает на одежду и еду, за 2015 год выросло почти вдвое - с 22 до $39 \%$. Об этом сообщает сайт «Русская планета», ссылаясь на доклад ВЦИОМ.

По информации центра исследований, такие показатели идентичны показателям 2009 г., но тогда общая динамика была положительной. Максимальный уровень бедности был зафиксирован в 2004 году, а с 2005 года этот показатель начал уменьшаться, дойдя с отметки 49 до $22 \%$ в 2014 г. Как можно увидеть, только за прошлый год этот показатель увеличился почти вдвое» [1]. И хотя масштаб этих данных ряд специалистов подвергает сомнению, никто не будет спорить, что число бедных за 2015 г. все-таки увеличилось, что негативно влияет на рынок, способствует росту социальной напряженности в стране.

Очевидно, что такая динамика повлияет на решения, принимаемые российскими коммерческими банками в части стратегии и тактики своего развития. Одновременно банковский рынок становится все более конкурентным и характеризуется как «рынок покупателя», а не как «рынок продавца», что требует от коммерческих банков поиска новых подходов банковского обслуживания, ориентации на клиентоориентированные модели обслуживания, учет и дифференциацию потребностей разных клиентских групп.

Российские банки в последние годы сильно ориентированы на обслуживание розничных клиентов, но следует учитывать существенную дифференциацию разных групп частных лиц с учетом их поведенческих особенностей, нацеленных на разные потребности в банковском обслуживании и получение разных пакетов розничных банковских продуктов. Спрос на премиальное банковское обслуживание также зависит от типа финансового поведения частных лиц.

В литературе выделяются различные типовые профили клиентов и их поведенческие потребности, учитывающие важность таких финансовых параметров, как величина ежемесячного дохода, ежемесячных сбережений, величина финансовых активов домохозяйства (накопленное богатство). Можно выделить три типа поведенческих особенностей частных лиц [2. C. 32-33]. Частные лица с умеренными сбережениями выступают скорее как накопители, чем как рантье. Они стремятся делать вклады на большие сроки для получения максимального процента, но неохотно идут на размещение текущих сбережений, хотят скорее подкапливать, держа деньги «на руках», а затем размещать. Частные лица, относящиеся к «среднему классу» (именно их количество сокращается, пополняя число бедных, но именно они являются целевой 
группой ПБО), стремятся скорее сохранять и накапливать, чем быть рантье, так как проценты, начисляемые ежемесячно на вклад, существенно уступают по размеру ежемесячно откладываемым сбережениям. Они постоянно на что-нибудь копят: на покупку квартиры, автомобиля, мебели, бытовой техники, туристической путевки, оплаты обучения и др. Но могут также делать вклады на большие сроки, однако их цель - не ежемесячное снятие процентов для получения большого дохода, а способ застраховаться от планомерного снижения российскими банками процентных ставок. Они ценят возможность досрочного снятия средств без существенной потери процентов из-за возможности появления очень выгодного предложения покупки того или иного необходимого предмета, для приобретения которого делались накопления. Работа с богатыми клиентами (лица «с высокими сбережениями») обычно консервативна, поскольку ее целью является не получение высокой прибыли, а сохранение сбережений клиентов. Проценты, начисляемые ежемесячно на вклад, сопоставимы по размеру с ежемесячными расходами, поэтому в первую очередь необходим вклад, обеспечивающий функционал «рантье». Они могут располагать значительной денежной суммой «на руках», поэтому при отъезде в отпуск за границу или на летнюю дачу стараются не держать деньги в квартире, а разместить посредством короткого вклада, рассматривая его не как источник дохода, а как аналог депозитного сейфа. Однако клиент осторожен, с момента, когда менеджер банка знакомится с клиентом, до момента, когда клиент осмеливается принести деньги в банк, в среднем проходит полгода.

По мнению Н.Е. Бровкиной, модель обслуживания физических лиц коренным образом отличается от модели банковского обслуживания предприятий. Физические лица более неоднородны и преследуют разные цели при получении банковских услуг. Н.Е. Бровкина выделяет три основные группы клиентов среди физических лиц: розничные клиенты, клиенты среднего класса, состоятельные клиенты. Розничные клиенты, в свою очередь, могут состоять из трех подгрупп: наименее состоятельные (сбережений не имеют, нацелены на получение потребительских кредитов), основная подгруппа - розничные клиенты, имеющие средний доход (имеют небольшие сбережения, необходимость в кредите обусловлена потребностями, выходящими за рамки текущих потребностей), розничные клиенты, имеющие доход выше среднего (клиенты среднего возраста, имеют сбережения, потребность в кредите возникает вследствие непредвиденных событий) [3. С. 46-47]. Следует согласиться с подобным подходом к дифференциации клиентской базы.

C позиций премиального банковского обслуживания банку интересны клиенты среднего класса и состоятельные лица, хотя конкурентная борьба вынуждает банки, особенно в регионах, обращать внимание и на розничных клиентов с доходом чуть выше среднего. И хотя банки предлагают им не всегда «полные» премиальные пакеты, но все-таки стремятся дифференцировать их потребности, а в рамках различных пакетных решений включать премиальные предложения классических банковских услуг (например, расчетные и кредитные карты и др.). Наверное, это позволило некоторым авторам утверждать, что за «премиальным обслуживанием маскируется просто качественный сервис» [4].

При этом существует значительная дифференциация не только в подходах к установлению количественных параметров целевого клиентского сегмента, но отсутствует единый подход в терминологическом определении. Зачастую в литературе отождествляются понятия «премиальное банковское обслуживание», Private Banking и др. [5]. Обосновано использование термина «эксклюзивное банковское обслуживание» (ЭБО) [6]. В диссертации А.А. Еделькиной проведено также разграничение понятий, связанных с данным сегментом банковского рынка. Результаты данного исследования обобщены в таблице (составлено по: [6. С. 20, 29]).

Следует в целом согласиться с представленным подходом к классификации данного сегмента рынка, хотя в РФ пока нет такой четкой дифференциации по сегментам, не все услуги в полной мере востребованы соответствующими группами потребителей, различаются и пороги входа на этот сегмент рынка по сравнению с западной практикой. Это вполне оправданно, так как на мировом рынке ЭБО сложились разные модели, обладающие национальной спецификой в силу различных традиций, правовых особенностей и др. Выделяются три модели: североамериканская, европейская, азиатская [6. С. 127].

В России модели премиального банковского обслуживания могут обладать разными чертами и подходами на уровне столицы и регионов. По мнению К. Селянина, «для федеральных банков, как правило, интересны клиенты с суммами от \$1 млн, у нас на премиальный уровень сможет претендовать клиент, имеющий \$30-100 тыс. Кроме того, их отличает большая гибкость, возможность подстроиться под клиента в своих услугах» [4]. Наверное, можно согласиться с тем, что клиенты в столице и регионах могут иметь разные потребности в услугах, располагают разными суммами накоплений, но вряд ли эти различия будут увеличиваться, скорее они будут нивелироваться. 
Классификация сегментов рынка ЭБО

\begin{tabular}{|c|c|c|c|c|}
\hline $\begin{array}{c}\text { Формы управления } \\
\text { личным капиталом } \\
\text { клиента }\end{array}$ & Категории клиентов & $\begin{array}{l}\text { Порог } \\
\text { входа в } \\
\text { мире, } \\
\text { млн } \\
\text { долл. }\end{array}$ & Базовый набор услуг и продуктов & $\begin{array}{c}\text { Примеры } \\
\text { поставщиков } \\
\text { услуг }\end{array}$ \\
\hline $\begin{array}{l}\text { Семейный } \\
\text { (Family office) }\end{array}$ & $\begin{array}{l}\text { Сверхсостоятельные } \\
\text { ультраобеспеченные } \\
\text { (UHNWI - ultra high net } \\
\text { worth individuals) }\end{array}$ & $30-50$ & $\begin{array}{l}\text { Классические банковские услуги. } \\
\text { Инвестиционное консультирование и } \\
\text { управление. } \\
\text { Наследование, налоговое планирование и } \\
\text { юридическое консультирование. } \\
\text { Услуги по управлению стилем жизни } \\
\text { клиента. } \\
\text { Сопровождение бизнеса }\end{array}$ & $\begin{array}{l}\text { Управляющая } \\
\text { компания, } \\
\text { финансовые } \\
\text { группы }\end{array}$ \\
\hline $\begin{array}{l}\text { Эксклюзивное } \\
\text { банковское } \\
\text { обслуживание (Private } \\
\text { Banking) }\end{array}$ & $\begin{array}{l}\text { Состоятельные / обес- } \\
\text { печенные (HNWI -high net } \\
\text { worth individuals) }\end{array}$ & $1-30$ & $\begin{array}{l}\text { Классические банковские услуги. } \\
\text { Инвестиционное консультирование и } \\
\text { управление. } \\
\text { Наследование, налоговое планирование и } \\
\text { юридическое консультирование. } \\
\text { Услуги по управлению стилем жизни } \\
\text { клиента }\end{array}$ & $\begin{array}{l}\text { Частные } \\
\text { банковские дома, } \\
\text { финансовые } \\
\text { группы, } \\
\text { универсальные } \\
\text { банки }\end{array}$ \\
\hline $\begin{array}{l}\text { Управление } \\
\text { состоянием } \\
\text { management) }\end{array}$ & $\begin{array}{l}\text { Верхний сегмент среднего } \\
\text { класса, } \\
\text { перспективы (Mass affluent } \\
\text { / Affluent) }\end{array}$ & $0,1-1$ & $\begin{array}{l}\text { Классические банковские услуги. } \\
\text { Инвестиционное консультирование и } \\
\text { управление. } \\
\text { Наследование, налоговое планирование и } \\
\text { юридическое консультирование }\end{array}$ & $\begin{array}{l}\text { Универсальные } \\
\text { (розничные) } \\
\text { банки, } \\
\text { инвестиционные } \\
\text { банки, } \\
\text { финансовые } \\
\text { группы }\end{array}$ \\
\hline $\begin{array}{lr}\text { Премиальное } & \\
\text { банковское } & \\
\text { обслуживание } \\
\text { banking / VIP- } \\
\text { banking) }\end{array}$ & $\begin{array}{l}\text { Верхний сегмент среднего } \\
\text { класса, } \\
\text { перспективы (Mass affluent } \\
\text { / Affluent) }\end{array}$ & $\begin{array}{c}0,05- \\
0,08\end{array}$ & $\begin{array}{l}\text { Классические банковские продукты с } \\
\text { индивидуальными условиями по } \\
\text { продуктам: вкладам, картам, кредитам, } \\
\text { переводам. } \\
\text { Особый статус: услуги персонального } \\
\text { менеджера, возможность приходить в } \\
\text { банк без очереди, быстрый доступ к } \\
\text { различным службам клиентской } \\
\text { поддержки }\end{array}$ & $\begin{array}{l}\text { Универсальные } \\
\text { (розничные) } \\
\text { банки, } \\
\text { финансовые } \\
\text { группы }\end{array}$ \\
\hline $\begin{array}{l}\text { Управление } \\
\text { финансовыми } \\
\text { активами } \\
\text { management) }\end{array}$ & $\begin{array}{l}\text { Средний класс и } \quad \text { выше } \\
\text { (Middle class), a } \\
\text { институциональные } \\
\text { инвесторы }\end{array}$ & $\begin{array}{c}0,03- \\
0,05\end{array}$ & $\begin{array}{l}\text { Инвестиционное консультирование } \\
\text { управление финансовыми активами. } \\
\text { Классические банковские услуги и др. }\end{array}$ & $\begin{array}{l}\text { Инвестиционные } \\
\text { компании, } \\
\text { управляющие } \\
\text { компании, } \\
\text { финансовые } \\
\text { консультанты, } \\
\text { универсальные } \\
\text { банки }\end{array}$ \\
\hline
\end{tabular}

Кроме того, должны быть общие подходы, закономерности, стандарты в обслуживании клиентов в рамках премиального банковского обслуживания (ПБО), в частности для банков, действующих на федеральном и региональном уровне. Вряд ли, например, Сбербанк или ВТБ 24 будут предлагать разные пакеты услуг ПБО для своих клиентов в Москве, СанктПетербурге или регионах, хотя «порог входа» может быть снижен для региональных клиентов, если банк заинтересован в привлечении новой клиентуры. При этом порог не следует чрезмерно занижать, ведь, по мнению А.И. Гусева, «качественное обслуживание на уровне традиционного Private Banking можно оказать, только если один персональный менеджер постоянно обслуживает не более 10-20 клиентов, а дальше начинается нивелирование качества» [7]. При этом в России наблюдается дефицит квалифицированных персональных менеджеров, поэтому чрезмерное снижение порога входа приведет к явному снижению качества.
По мнению А.А. Еделькиной, на российском рынке ЭБО наблюдается значительный разброс пороговых значений размера капитала состоятельного лица, необходимый для обслуживания по программам ЭБО. Входной порог для состоятельных клиентов в отечественных банках сейчас составляет в среднем \$200 тыс., но по мере сближения данного показателя с мировыми стандартами он может подняться до \$0,5-1 млн [6. С. 145].

В июле 2015 г. был опубликован отчет о банковском премиальном обслуживании, проведенный Frank Research Group [8]. Специалисты Frank Research Group подразделяют весь рынок на три сегмента: массовый сегмент (0,7-1 млн руб.), VIP или Private Bank (30-40 млн руб.) и премиальный сегмент (Affluent) (занимает промежуточное место - условно от 2,5-3 до 8-10 млн руб.). Ограниченность VIP-сегмента подтолкнула банки к дальнейшей сегментации, произошло выделение нового «серединного» сегмента affluent. Банки начали выделять подбренды, формировать отдельный подход и 
стратегию для сегмента. Банки определили пороги входа между сегментами, при этом на рынке отсутствует единый подход к сегментации клиента. Для целей исследования о премиальном банковском обслуживании были установлены следующие критерии определения сегмента: уровень ежемесячного дохода от 150 000-500 000 руб. в месяц, 200 000-250 000 руб. в среднем, объем размещенных средств от 2 до 8 млн руб., 3-4 млн руб. в среднем [8].

Два обстоятельства обусловливают повышенный интерес российских банков к премиальному клиенту: возможность получения высокого дохода - премиальные клиенты формируют 40-60 \% дохода розницы и обладают высокой степенью кризисоустойчивости: так, когда общие доходы на рынке падают, данная клиентская группа характеризуется устойчивостью доходов; наличие высокого потенциала сегмент не сформирован до конца, не определены четко его границы, что дает возможность увеличения за счет роста среднего класса или включения части (лиц с доходами выше среднего) массового сегмента, который, как мы отмечали, также является неоднородным. Это подтверждают и сами участники рынка. Например, «Альфа-Банк оценивает потенциал рынка как высокоперспективный. ...Так, в Промсвязь-банке $40 \%$ дохода розничного бизнеса формирует премиальный сегмент. В Абсолют Банке депозиты VIP-клиентов на данный момент составляют 70 \% от всего объема депозитов физических лиц» [5]. Среди части клиентов также существует тенденция к консолидации своих накоплений в одном банке, несмотря на пределы гарантирования со стороны ACB. Это приводит к тому, что «клиент в первую очередь ориентируется на надежность самого банка. Сначала он выбирает для себя бренд, которому он готов доверить свои сбережения. Затем, безусловно, продуктовое предложение. Важны продукты по управления капиталом диверсифицированный, правильно построенный портфель для клиента. И, конечно, сервиспривилегии» [9].

Особенностью обслуживания премиальных клиентов следует считать наличие потребности не только в классических банковских услугах и инвестиционном планировании, но и в дополнительных услугах, в том числе нефинансового свойства. Как правило, премиальные клиенты хотят получать в предлагаемом пакете кроме классических банковских услуг (вклады, карты, кредиты, расчетно-кассовое обслуживание) также соответствующий уровень сервиса и статуса (персональный менеджер, выделенная телефонная линия, VIP-зона обслуживания, статусные привилегированные карты), возможность сохранения и приумножения семейного капитала (персональное финансовое планирование, премиальные вклады с повышенным процентом, возможность исполь-зования других финансовых инструментов с широким спектром предложений от коллективных до индивидуальных инвести-ционных решений, особые условия по кредитам), дополнительные сервисы и нефинансовые услуги (членство в клубах, наличие программ скидок с партнерами банка, дополнительные консьерж-услуги для путешествующих, страховые продукты, другие привилегии).

На томском банковском рынке в наибольшей степени этим требованиям соответствуют предложения от Сбербанка РФ Сбербанк Премьер и Сбербанк Первый. Томское отделение Сбербанка не только предоставляет персонального менеджера, но и в отличие от других банков организует обслуживание своих премиальных клиентов (по пакету Сбербанк Первый) в отдельном офисе, что позволяет также удовлетворять потребности этой группы клиентов не только в статусности и высоком сервисе обслуживания, но и в конфиденциальности. На региональном рынке банки (например, Сбербанк РФ, Альфа-Банк, Промсвязьбанк) предлагают более низкие и гибкие пороги входа, чем в столице. Банки стремятся максимально дифференцировать сегменты премиального обслуживания, предлагая различные пакеты услуг в зависимости от величины средств, размещенных в банке. Такая детальная сегментация, с одной стороны, дает возможность привлекать дополнительные группы клиентов, но с другой может распылять усилия банка и привести к удорожанию обслуживания для самого банка.

По итогам исследования Frank Research Group [8] были получены следующие результаты: по расчетам Frank Research Group первое место занимает Райффайзенбанк с пакетом персонального банковского обслуживания «Premium Banking» (40 баллов), второе место - за АльфаБанком - пакет услуг «Максимум» (36 баллов), третье - ВТБ 24 с пакетом услуг «Привилегия» (35 баллов), четвертое - Промсвязьбанк с премиальной программой «Orange Premium Club» (34 балла), пятое - Сбербанк РФ с форматом премиального банковского обслуживания «Сбербанк Премьер» (33 балла). По мнению банковского сообщества результаты получились следующими: первое место досталось - АльфаБанку, второе - Райффайзенбанку, третье Сбербанку, четвертое - ВТБ 24, замыкает список лидеров Ситибанк (Citibank) с индивидуальным банковским обслуживанием Citigold. В рейтинге Frank Research Group они делят пятое место по баллам со Сбербанком. Нам представляется интересным провести анализ томского рынка премиального банковского обслуживания и, 
выявив лидеров, сравнить их с данным исследованием и его результатами. По субъективным ощущениям на томском рынке скорее всего лидировать будет Сбербанк. В ближайшее время мы планируем провести сравнительный анализ томского рынка премиального банковского обслуживания.

В исследовании, проведенном Frank Research Group [8] относительно итогов и перспектив развития премиального банковского обслуживания, также констатируется, что рынок развивается: совершенствуется наполнение премиальных программ, растут запросы клиентов, улучшается качество премиальных зон в офисах (появляются кабинеты индивидуальных менеджеров, выделяются отдельные офисы для обслуживания VIPклиентов).

В целом коммерческие банки, осваивающие сегмент премиального банковского обслуживания, должны руководствоваться следующими принципами: наличие и высокий уровень квалификации персональных менеджеров; высокая степень индивидуализации услуг и высокая степень вовлеченности клиента в процесс создания и получения услуги; высокий уровень сервиса в обслуживании; конфиденциальность в обслуживании; «широкий спектр продуктов и услуг, в том числе за счет использования принципа открытой архитектуры» [6. С. 33]; равноправные и долгосрочные отношения «банк-клиент»; диверсифицированный характер спроса.

На развитие мирового рынка премиального банковского обслуживания оказывают влияние и будут оказывать в обозримой перспективе следующие факторы: усиление конкуренции на рынке банковских услуг, законодательные изменения, снявшие жесткие ограничения с банков, активное развитие и проникновение финансовых банковских инноваций. Для России более значимы факторы конкуренции и инноваций, чем законодательные ограничения. Оказывают влияние также рост благосостояния и увеличение уровня доходов, увеличение средней продолжительности жизни, формирование спроса на индивидуализированные персональные банковские услуги. По мнению А.А. Еделькиной, российский рынок ЭБО можно отнести к развивающемуся по американской модели [Там же. С. 149].

На основе анализа литературы [6, 10-15] можно выявить специфику рынка премиального и эксклюзивного банковского обслуживания: большинство игроков этих сегментов рынка ориентируются на количество, а не на качество, которое подразумевает детальную сегментацию клиентов и соответствующий набор услуг; отсутствие опыта и традиций у российских владельцев крупного капитала передавать все активы в управление одному банку приводит к нестабильности клиентской базы и вынуждает банки работать с объемами активов, передаваемых под управление, близкими к рознице (на наш взгляд, в настоящее время эта тенденция подвергается корректировке, и все большее количество премиальных клиентов хотели бы работать с одним банком, с «брендом»); на российском рынке набор услуг в некоторых случаях определяется не потребительскими предпочтениями клиентов, а рыночной и политической ситуацией в России; если на рынках развитых зарубежных стран актуальными являются вопросы сохранения капитала (преобладают, следовательно, консервативные стратегии), то российские клиенты большое внимание уделяют его приумножению и нацелены на получение более высокого дохода; премиальные клиенты в России обладают сравнительно более невысокими размерами капитала по сравнению в западными, где их скорее бы отнесли к массовому сегменту, но существует тенденция сближения и нивелирования этих различий; как правило, потенциальный клиент зарубежного банка должен доказать собственную респектабельность, предоставить рекомендации, в то время как российские банки самостоятельно занимаются поиском клиентов и должны демонстрировать им возможности своего профессионального уровня по управлению их личным капиталом; российские банки имеют ограниченные возможности предложения продуктов, используемых на международных рынках, но при этом российские банки демонстрируют лучшее понимание национальной специфики и национальных особенностей ведения бизнеса и предоставляют более широкий спектр нефинансовых услуг.

К недостаткам, которые придется преодолевать российским банкам в этом сегменте рынка, относятся: качество услуг не должно определяться только их разнообразием; следует решать вопрос с дефицитом квалифицированных персональных менеджеров; следует стремиться соответствовать мировым стандартам премиального и эксклюзивного банковского обслуживания, обеспечивая обособленность VIP-подразделений от других подразделений банка, что будет обеспечивать конфиденциальность и достойный уровень сервиса; отсутствует эффективная стратегия сегментирования премиальных клиентов; существует недостаточный уровень доверия к банковской системе в целом. Нужно отметить также слабое законодательное регулирование этого сегмента рынка, что является, с одной стороны, недостатком, а с другой - дает возможности для саморегулирования, что нашло отражение в появлении в 2003 г. Комитета по 
частному банковскому обслуживанию при Ассоциации российских банков, но в 2005 г. деятельность его была приостановлена.

В целом следует констатировать, что такой сегмент рынка, как «премиальное банковское обслуживание», необходим, и он будет развиваться в условиях жесткой конкурентной борьбы. Существует необходимость как практических исследований этого сегмента рынка, позволяющих выявлять его возможности и перспективы, так и теоретических исследований, направленных на устранение терминологических различий и поиска эффективной методологической базы для сегментирования премиальных клиентов. На уровне практической деятельности необходимо обеспечение адекватного правового поля, обеспечивающего защиту интересов как банков, так и их клиентов; а также комплекса мер по повышению квалификации кадров в сфере персональных банковских менеджеров во всех звеньях цепочки от вузов до самих банков (переподготовка, обучение и повышение квалификации в корпоративных университетах).

\section{Литература}

1. 55 миллионов бедных граждан в России. Электронный pecypc: http://www.metrprice.ru/another-news/55-millionovbednyh grazhdan-v-rossii

2. Владиславлев Д.Н. Как организовать клиентскую службу банка / Д.Н. Владиславлев. М.: Ось-89, 2005. 224 с.

3. Бровкина Н.Е. Актуальные проблемы банковского обслуживания физических лиц // Банковское дело. 2013. № 11. C. $45-50$.
4. Некоторые банки маскируют под премиальное обслуживание просто качественный сервис. Интервью с независимым финансовым аналитиком Селяниным Константином. 09.07.2015. Электронный ресурс: // http:// www. kommersant.ru/ doc/2764063.

5. Баженов Н. Особые условия // Бизнес-журнал. 2015. 7 сент. Электронный pecypc: http://b-mag.ru〈2015\ finance osobyie-usloviya

6. Еделькина A.A. Факторы развития мирового рынка эксклюзивного банковского обслуживания: дис. ... канд. экон. наук. М., 2015. Электронный pecypc: http:// istina.msu.ru/ media/dissertations

7. Гусев А.И. Российский рынок Private Banking системно заинтересовался розницей // Банковский ритейл. 2008. № 2.

8. Банковское премиальное обслуживание: 2015 год. Frank Research Group. Демонстрационная версия отчета. Электронный pecypc: http://www.frankrg.com/userfiles/ 867 Frank_RG.Premium (2015-07-23).

9. Носкова Е. Каприз за ваши деньги. Премиальные клиенты банков становятся более требовательными // Российская бизнес-газета. 2015. 28 июля. № 1008 (29).

10. Антонова В.Г. Особенности развития российского рынка индивидуального банковского обслуживания // Петербургский экономический журнал. 2014. № 1. С. 114-118.

11. Бровкина Н.Е., Ломако Ю.В. Что такое Private banking и тенденции его развития в России // Деньги и кредит. 2011. № 8. C. 53-57.

12. Гончаренко Н.В. Обслуживание состоятельных клиентов (Private Banking): зарубежный опыт и российские перспективы // Вестник Санкт-Петербургского университета. Сер. 5: Экономика. 2008. № 3. С. 81-89.

13. Гусев А.И. Private banking по-русски?! / А.И. Гусев. М.: Кнорус, 2013. 297 c.

14. Китаев А.А. Private Banking (частное банковское обслуживание) в России и перспективы его развития в регионах // Финансы и кредит. 2008. № 36. С. 29-34.

15. Коляда M.A. Адаптация Private banking в российской действительности // Вестник университета (Государственный университет управления). 2012. № 14-1. С. 193-197. 